\title{
Very Small Cerebellar Infarcts: Integration of Recent Insights into a Functional Topographic Classification
}

\author{
Laurens J.L. De Cocker ${ }^{a}$ Susanne J. van Veluw ${ }^{b}$ Mary Fowkes ${ }^{c}$ \\ Peter R. Luijten ${ }^{\mathrm{a}}$ Willem P.Th.M. Mali ${ }^{\mathrm{a}}$ Jeroen Hendrikse ${ }^{\mathrm{a}}$ \\ ${ }^{a}$ Department of Radiology, University Medical Center Utrecht, and bepartment of Neurology, Rudolf Magnus \\ Institute of Neuroscience, University Medical Center Utrecht, Utrecht, The Netherlands; ' $D e p a r t m e n t$ of Pathology, \\ Mount Sinai Medical Center, New York, N.Y., USA
}

\section{Key Words \\ Cerebellar infarction - Lacunar infarct · Neuroimaging · Border zone infarct - Watershed infarction - End zone infarct · Nonterritorial infarct · Territorial infarct $\cdot$ Larsell classification · Microinfarct}

\begin{abstract}
Background: Very small cerebellar infarcts (diameter $<2 \mathrm{~cm}$ ) are a frequent finding on MRI. With an increasing scientific interest in cerebral microinfarcts, very small infarcts in the cerebellum deserve more of our attention as well. The goal of the present article was to review infarct terminology and mechanisms, as well as to critically appraise the current classification system for very small cerebellar infarcts. Methods: A search strategy was designed to identify all relevant studies on very small cerebellar infarcts in the English language. This search was restricted to papers published up to February 21,2013 . Studies were initially identified from the MEDLINE/ PubMed database using the search terms 'small cerebellar infarct', 'lacunar infarct', 'microinfarct', 'end zone infarct', 'border zone infarct', 'watershed infarct', 'territorial infarct', and 'nonterritorial infarct'. Furthermore, a similar search strategy was directed to identify all relevant articles on (descriptive and functional) neuroanatomy and neuroimaging
\end{abstract}

of the cerebellum. Results: Very small cerebellar infarcts have been referred to as lacunar infarcts, as junctional, border zone or watershed infarcts, as nonterritorial infarcts, as very small territorial or end zone infarcts, or simply as (very) small cerebellar infarcts. Since the original clinicoradiological study on these small infarcts, the classification into border zones remains in common use. This classification is based upon the assumption that these infarcts occur secondary to low flow in between arterial perfusion territories, where flow is believed to be the lowest. Later studies, however, have suggested occlusion of small (end-) arteries as a prerequisite for the pathogenesis of even small cerebellar infarcts, with low flow merely as a potential contributor. Therefore, it is likely that infarcts may as well occur in a nonborder zone distribution. Moreover, the classification into border zones may be considered unreliable since the location of border zones is highly variable among individuals and is not known in a particular patient. Recently, a functional topographic organization has been found in the cerebellum with evidence for a motor-nonmotor dichotomy between the anterior and posterior lobe. Since the cerebellar lobes can be easily and reliably distinguished with both $\mathrm{CT}$ and $\mathrm{MRI}$, we recommend the classification of very small cerebellar infarcts according to topographic location. Conclusion: There are several fundamental concerns with the current classification of very

\section{KARGER}

E-Mail karger@karger.com www.karger.com/ced
(C) 2013 S. Karger AG, Basel

$1015-9770 / 13 / 0362-0081 \$ 38.00 / 0$
Laurens J.L. De Cocker

Department of Radiology, University Medical Center Utrecht Heidelberglaan 100

NL-3584 CX Utrecht (The Netherlands)

E-Mail l.j.l.decocker@umcutrecht.nl 
small cerebellar infarcts according to border zones, which we would like to overcome by recommending a new classification system based on topography. This will allow for a reliable and reproducible way of classifying very small cerebellar infarcts and is expected to improve clinicoradiological correlation.

Copyright $\odot 2013$ S. Karger AG, Basel

\section{Introduction}

Very small cerebellar infarcts are a frequent finding on modern neuroimaging [1]. Originally, very small cerebellar infarcts were called lacunar infarcts based on neuropathological findings [2]. With the advent of CT and MRI, many confusing terms have come across to categorize very small cerebellar infarcts (diameter $<2 \mathrm{~cm}$ ). These infarcts are currently being referred to as either junctional, border zone or watershed infarcts [1], nonterritorial infarcts $[3,4]$, very small territorial infarcts or end zone infarcts [5], or simply as (very) small cerebellar infarcts. The goal of this article is to add clarity to the terminology and pathogenesis of these infarcts. We also recommend the classification of very small infarcts according to their topographic location in the cerebellum instead of a classification in terms of perfusion territories or border zones.

\section{Anatomy}

\section{Structural Anatomy}

The cerebellum (Latin for 'little brain') is located in the posterior fossa of the skull. The cerebellum consists out of a midline vermis and two lateral hemispheres, and it has three surfaces. The anterior or petrosal surface faces the os petrosum in front, the superior or tentorial surface is covered by the tentorium above, and the posterior or occipital surface is bounded by the occiput behind. The cerebellum is composed of three lobes; the anterior lobe (lobules I-V according to the revised Larsell classification), the posterior lobe (lobules VI-IX), and the flocculonodular lobe (lobule X) [6]. The anterior lobe is separated from the posterior lobe by the primary fissure, which is easily identified in the axial and midsagittal plane as the deepest and thickest fissure in the superior part of the vermis (fig. 1,2). There are two prominent fissures within the posterior lobe of the cerebellum; the posterior superior fissure and the great horizontal fissure (fig. 1,2). The posterior superior fissure runs parallel and posterior to the primary fissure in the superior surface of the cere-
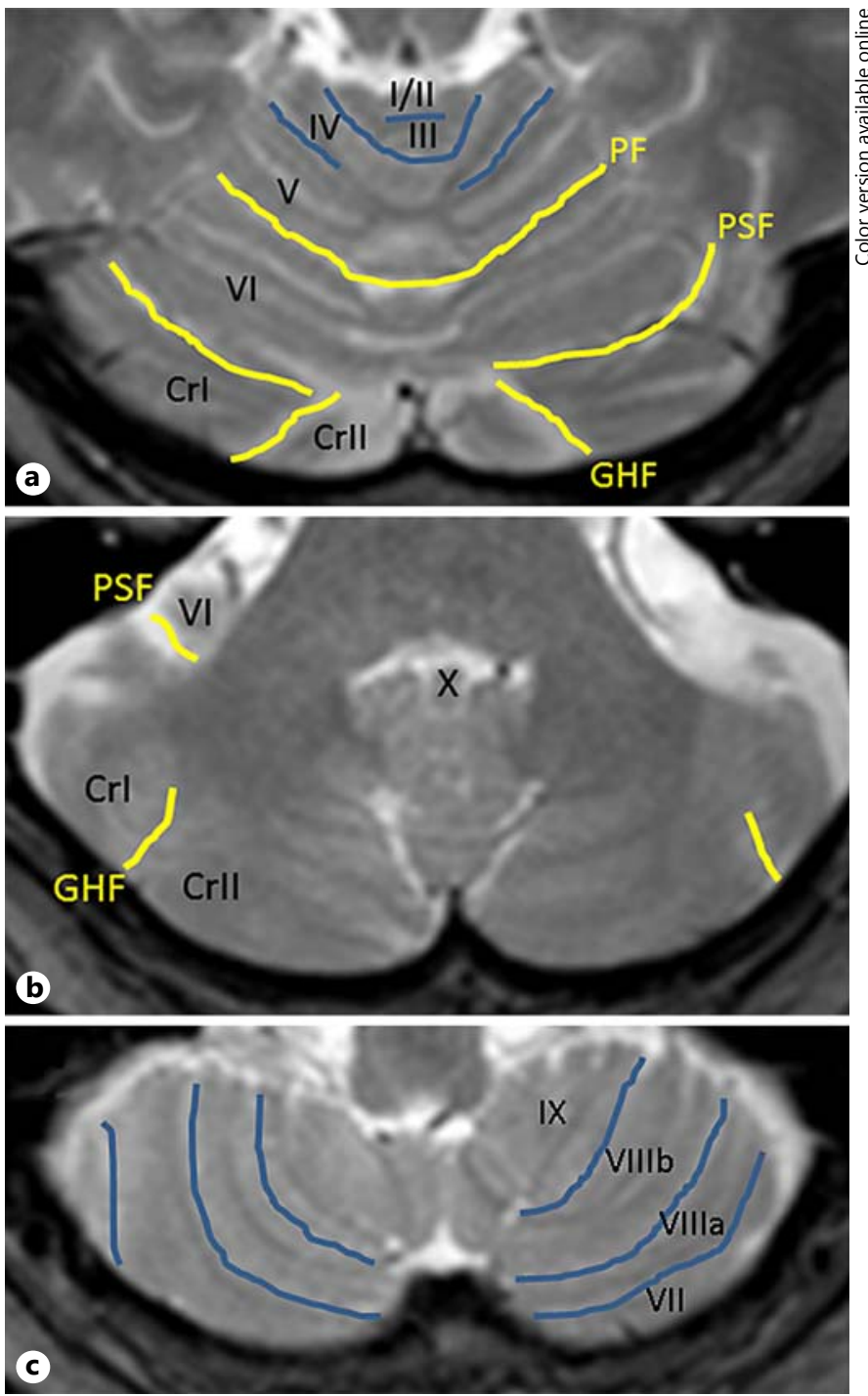

Fig. 1. Selection of three key MR images for the lobar and lobular classification of the cerebellum (according to Schmahmann et al. [6]), at the level of the midbrain (a), pons (b), and medulla oblongata (c). The fissures visualized in yellow are usually the most prominent and have a characteristic configuration. The primary fissure $(\mathrm{PF})$ is the largest fissure in the midline and divides the cerebellum into an anterior and a posterior lobe. The posterior superior fissure (PSF) runs parallel and posterior to the PF in the posterior lobe. The great horizontal fissure (GHF) forms an acute angle with the former fissures. Other fissures are shown in blue. Lobules indicated are lobules I-IX, Crus I (CrI), and Crus II (CrII). See figure 2 for the flocculus (hemispheric part of lobule $\mathrm{X}$ ).

bellum. The great horizontal fissure runs together with the posterior superior fissure in the midline. More laterally, it slopes inferiorly in the posterior surface of the cerebellum. Lobule VI is easily recognized as the area in between the primary fissure and the posterior superior fis- 

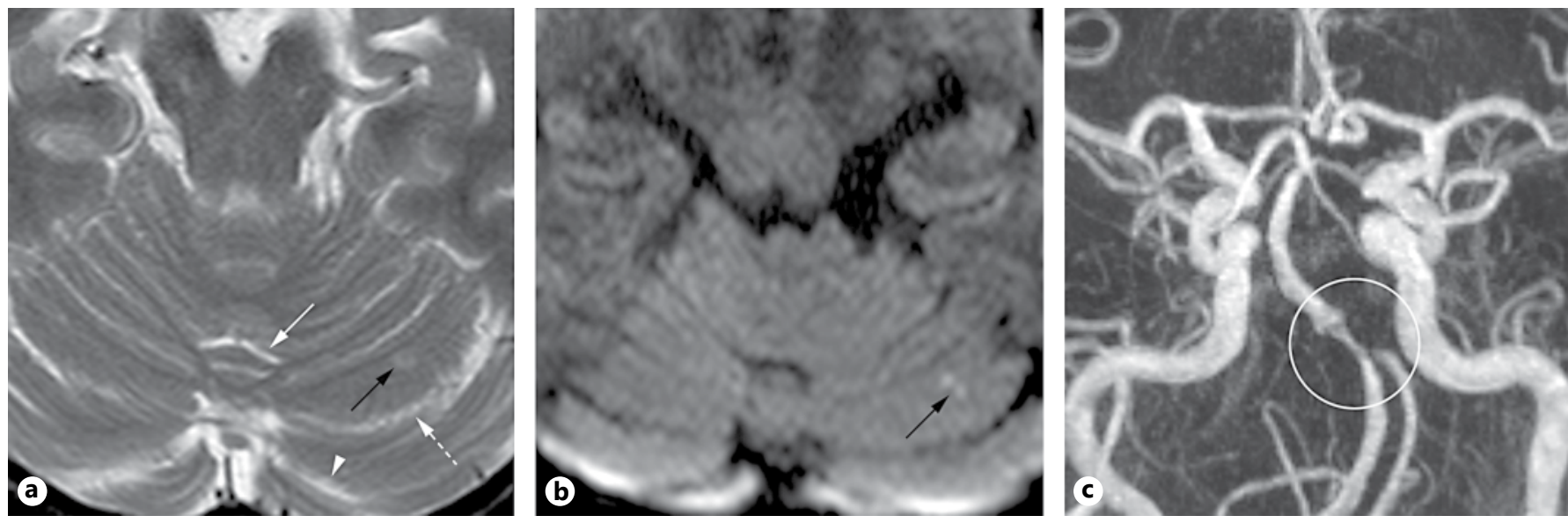

Fig. 2. T2WI (a) and DWI (b) show a very small acute infarct (black arrow) in between the primary fissure (arrow) and the posterior superior fissure (dashed arrow), situating the lesion in the posterior lobe in lobule VI. Also notice the great horizontal fissure (arrowhead). c MR angiogram shows a tight stenosis of the distal left vertebral artery and proximal basilar artery (encircled). sure (fig. 1, 2) [6]. The flocculonodular lobe (lobule X) is composed of the nodulus in the midline (fig. 1,3) and the flocculus (fig. 3 ) in the cerebellar hemispheres.

\section{Arterial Anatomy and Perfusion Territories}

The cerebellum mainly receives arterial blood supply from three paired arteries, although variant arterial anatomy is common. The posterior inferior cerebellar artery (PICA) usually arises from the distal vertebral artery and supplies the posterior surface of the cerebellum. The anterior inferior cerebellar artery (AICA) arises from the first or second thirds of the basilar artery. The territory perfused by the AICA varies in reciprocity with the PICA and superior cerebellar artery (SCA) [7]. It may be confined to the anterior surface, but the AICA may also supply lateral portions of the posterior and/or superior surface of the cerebellum. The SCA arises from the distal basilar artery and supplies the superior surface of the cerebellum from lateral to medial, unlike the PICA which supplies the inferior surface from medial to lateral. Circumferential branches of the PICA, AICA and SCA run nearly perpendicular to the cerebellar folia on the surface of the cerebellum. Small perforating arteries branch off from the circumferential arteries to penetrate the cerebellum. Anastomoses between the circumferential arteries of PICA, AICA and SCA are constantly present among individuals $[7,8]$.

\section{Functional Neuroanatomy}

It has been known for a long time that cerebellar functions include coordination of gait, extremity and eye movement, and articulation. Recent studies have linked the cerebellum with both cognitive and emotional processes as well. Moreover, there is now evidence for a topographic organization of cerebellar functions [9]. A dichotomy between motor and nonmotor functions has been found in the cerebellum based on anatomical, functional and neuropsychological studies [10]. Sensorimotor function has been found primarily in the anterior lobe (lobule I-V) with a second representation in lobule VIII, while cognitive processing (nonmotor function) is represented in the posterior lobe (lobule VI and VII; fig. 1). Lobule VI, which is the part of the posterior lobe closest to the anterior lobe, is thought to play an intermediary role in both motor and nonmotor (cognitive) functions (fig. 1,2) [11]. The posterior lobe of the vermis forms part of the limbic cerebellum.

\section{Pathogenesis}

'Very small (border zone) cerebellar infarcts' was the title of the original retrospective clinicoradiological study on very small cerebellar infarcts [1]. This study failed to establish a definite correlation between the location of these small infarcts and a stroke mechanism, though a thromboembolic source was identified in over half of the 47 patients. Notwithstanding mentioning 'border zone infarcts' in the title of the original article, the study left undecided if these infarcts represent either border zone infarcts or end zone infarcts. A second study specifically addressed the causes and mechanisms of cerebellar infarcts [3]. This and other studies showed that cardioem- 

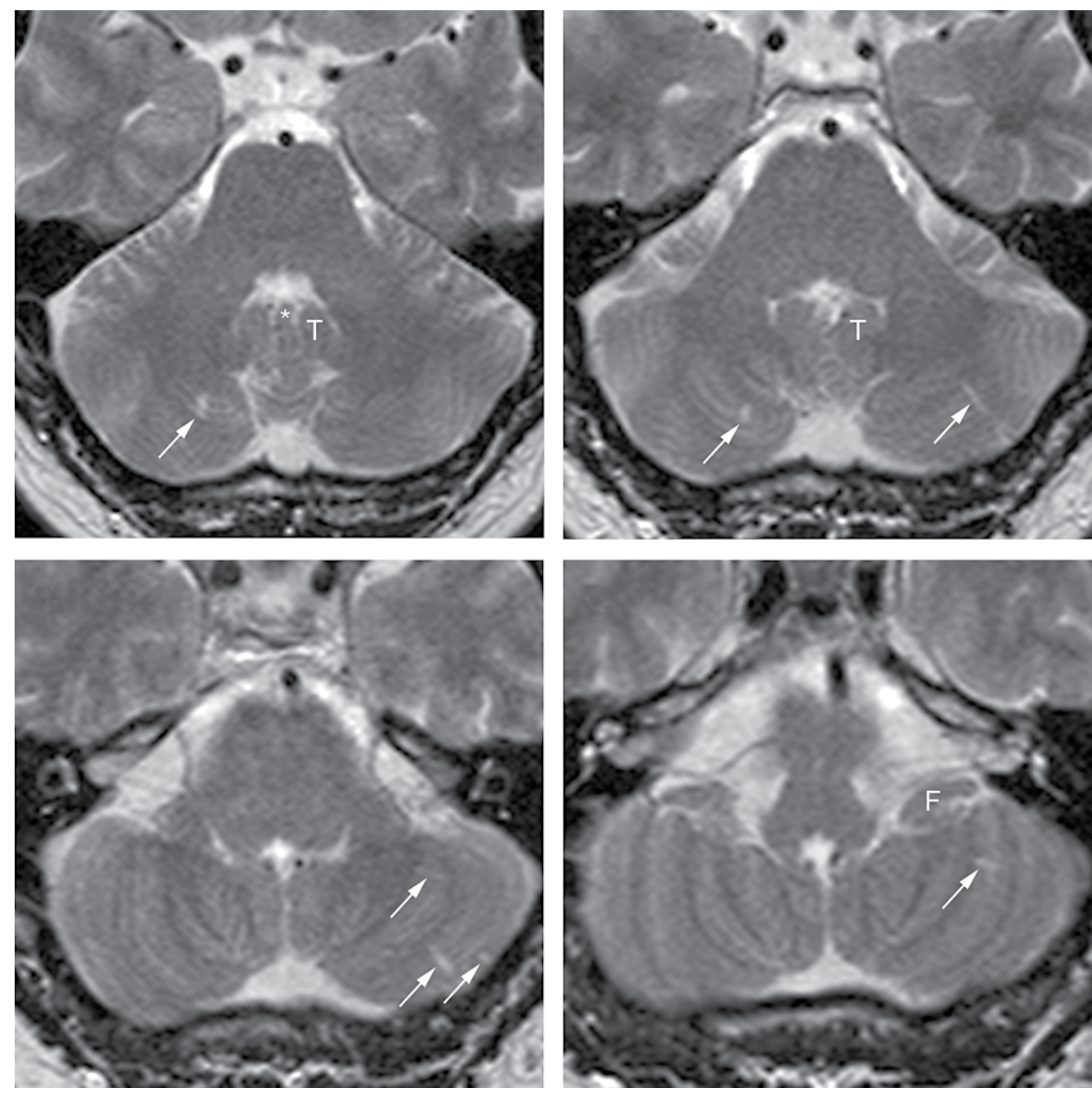

Fig. 3. Axial T2WI show multiple chronic infarcts in the left cerebellar hemisphere and one similar infarct on the right (arrows). The lesions are below the level of the primary fissure (not shown) and are therefore situated in the posterior lobe. Also indicated are the nodulus (asterisk) in between the tonsils (T), and the flocculus (F).

bolism and large vessel disease are the main causes of both large and small cerebellar infarcts [5, 12-17]. Amarenco et al. [3] also found a slightly higher incidence of a hypercoagulable or prothrombotic state in patients with small cerebellar infarcts as compared with patients with larger cerebellar infarcts. The latter finding made the authors reason that the occlusion of small distal arterioles may be the direct cause of small cerebellar infarcts, rather than hypoperfusion ('low flow') [3]. It was therefore postulated that small cerebellar infarcts in fact represent very small territorial (or end zone) infarcts. Equally impor- tant, this study also for the first time suggested that larger and smaller cerebellar infarcts essentially are the same, only differing from each other by the size of the clot causing the infarct. Despite these new insights, the authors of the article held on to the term 'non-territorial infarcts' to denote small cerebellar infarcts, as opposed to the larger 'territorial' infarcts. The term 'non-territorial infarcts' was later criticized, and it was proposed to use the term 'very small territorial infarcts' instead [5]. The use of the latter term emphasizes that larger and very small territorial infarcts are closely related. It should be noted that 
hypoperfusion and microembolism are not mutually exclusive, but likely complementary and interrelated instead [18]. The washout of small emboli may be hampered by a diminished flow, thereby contributing to the infarct $[18,19]$. Some studies presume that intrinsic small vessel disease might account for a small minority of small cerebellar infarcts as well, especially as a diagnosis of exclusion in patients with hypertension, absence of angiographic disease, and no evidence of an embolic source from the heart $[4,13]$. Nevertheless, this has never been confirmed with pathological correlation in the cerebellum. Finally, it should be mentioned that small cerebellar infarcts have been associated with migraine with aura as well $[20,21]$. Though the exact mechanism remains unclear at present, it has been recently suggested that migraine-related cerebellar infarcts might be attributed to a combination of altered autoregulation and additional factors such as the end artery cerebellar angioarchitecture [22].

\section{Pathology}

Since small cavitations in the cerebellum were first identified on postmortem pathology studies, they were originally called lacunar infarcts [2]. These studies lacked clinical correlation though. Cerebellar infarcts that were studied clinically and that had pathologic correlation almost exclusively included large infarcts with a dramatic clinical course (which enabled postmortem pathologic correlation) $[23,24]$. Many cerebellar infarcts with a benign clinical course remained unrecognized, even in the CT scan era [23]. With the advent of MRI, clinicopathological studies made way for clinicoradiological correlation studies, without pathologic confirmation. There are no reports on radiologic-pathologic correlation of these small infarcts. As a result, only little is known about the pathology of very small cerebellar infarcts. It is not known at present how many of these infarcts go on to cavitate in the chronic phase and eventually result in a lacune with surrounding gliosis after healing. As a side, notice that the term 'very small cerebellar infarcts' also encompasses cerebellar infarcts at the smallest end of the spectrum (fig. 2). These may be considered cerebellar microinfarcts. Microinfarcts are defined as microscopic infarcts which are found on histopathological examination of the postmortem brain [25]. Some of these microinfarcts can now be detected on neuroimaging in vivo as well, mainly due to the advent of diffusion-weighted imaging (DWI) and high-field strength MRI $[26,27]$.

Functional Topographic Classification of Very Small Cerebellar Infarcts

\section{Clinical Presentation}

Cerebellar infarcts typically present with nonspecific symptoms such as dizziness, nausea, vomiting, unsteady gait, and headache. Neurological signs associated with cerebellar infarcts include dysmetria, dysarthria, ataxia, and nystagmus [28]. Besides the cerebellar motor syndrome, it has now been shown that patients with cerebellar infarcts can also present with the cerebellar cognitive affective syndrome, which includes executive, visual spatial, and linguistic impairments, and affective dysregulation $[10,29,30]$. In general, small cerebellar infarcts present with the same (though less severe and less extensive) clinical manifestations as larger infarcts [3]. Some small cerebellar infarcts, especially those that occur in the territory of the posterior cerebellar artery, may be silent or present with only subtle cerebellar findings [31].

\section{Classification}

\section{Traditional 'Border Zone' Classification}

Large cerebellar infarcts have traditionally been classified in terms of the affected artery (PICA, AICA, or SCA), while very small cerebellar infarcts have traditionally been classified along the presumed border zone locations in between the three main cerebellar perfusion territories $[1,5,32,33]$. According to this principle, very small cerebellar infarcts were originally classified into five subgroups [1]. A later study suggested the addition of a new subgroup because a substantial fraction of the very small infarcts did not fit into the original classification [5].

\section{Need for a Different Classification}

There are several fundamental concerns with the classification of small infarcts into one of the border zone areas. First, for the reasons we have already discussed, it is likely that many small infarcts are small territorial infarcts that may not always occur in a border zone distribution. Secondly, arterial perfusion territories vary considerably among individuals, and these territories cannot yet be identified in an individual patient [7]. Although Tatu et al. [34] provided sections through the brain stem and cerebellum for visual correlation of perfusion territories with neuroimaging studies, such a perfusion territory atlas does not allow an accurate distinction of the different arterial perfusion territories (and the border zones in between them) in an individual patient. It is therefore impossible to accurately categorize a very small infarct as 
Table 1. Proposed classification of very small cerebellar infarcts according to anatomical location in the cerebellum

\begin{tabular}{|c|c|c|}
\hline \multicolumn{3}{|c|}{ Lobar classification (clinical purposes) } \\
\hline Anterior lobe & anterior vermis & anterior hemisphere \\
\hline Posterior lobe & posterior vermis & posterior hemisphere \\
\hline Flocculonodular lobe & nodulus & flocculus \\
\hline \multicolumn{3}{|c|}{ Lobular classification (research purposes) } \\
\hline Flocculonodular lobe & lobule X (nodulus) & lobule X (flocculus) \\
\hline
\end{tabular}

This classification uses the anatomical MRI atlas of the cerebellum by Schmahmann et al. [6].

either a territorial or border zone infarct at present. Thirdly, vascular territories do not respect anatomical (and thus functional) boundaries as fissures [7]. As a result, the classification in function of arterial perfusion does not correlate well with clinical findings. It is impossible to predict the affected perfusion territory of a cerebellar infarct based on the patient's symptomatology [28]. Though the relative frequencies of some clinical manifestations vary among infarcts in different territories, they do not allow a reliable prediction of the infarcted arterial territory or border zone [28].

\section{Functional Topographic Classification}

For the reasons above, there is a need for a user friendly and more accurate classification of small cerebellar infarcts that offers better clinical correlation. In order to achieve this goal, we recommend the classification of small cerebellar infarcts according to their topography in either the anterior or posterior lobe of the vermis or cerebellar hemispheres, or, in the flocculonodular lobe (lobule X). For clinicoradiological correlation studies, it is useful to classify small anterior and posterior lobe lesions into more detail with the same system, i.e. in terms of affected lobules instead of affected lobes (fig. 1; table 1) [6].

\section{Neuroimaging}

Small cerebellar infarcts are usually easily distinguished by their orientation perpendicular to cerebellar fissures [35]. Cerebellar infarcts present as areas of hypodensity on CT and as areas of hyperintensity on T2weighted images (T2WI) [35]. CT typically fails to demonstrate the acute phase of infarcts, and therefore it is merely used to exclude other abnormalities such as hem- orrhage or mass lesions [36]. On MRI, small cerebellar infarcts are more conspicuous on T2WI than they are on fluid-attenuated inversion recovery images [38]. DWI has markedly increased the conspicuity of MRI to detect small acute infarcts and is positive within minutes after onset (fig. 2) [26, 39]. DWI also allows the accurate distinction between recent and older infarcts. In the chronic stage, infarcts usually present as a small cerebrospinal fluid (CSF)-filled cleft (fig. 3). Due to a high intrinsic contrast between brain parenchyma and CSF, even very small cerebellar infarcts are easily detected on T2WI in the chronic stage. Comparable-sized areas of gliosis, which are the hallmark of supratentorial microinfarcts [25], are much harder to detect on MR [27].

\section{Conclusion}

Very small cerebellar infarcts are a frequent finding on $\mathrm{CT}$ and even more on MR imaging. Since these infarcts were originally believed to arise secondary to low flow in a border zone location, they are traditionally being classified according to border zones in between perfusion territories. This traditional classification is based upon unclear pathophysiologic mechanisms, however. Moreover, it is not possible to identify the cerebellar border zones at present. In order to achieve uniform reporting and better clinicoradiological correlation, we recommend the use of a reliable classification system based on cerebellar topography. For clinical purposes, small infarcts can be classified according to their midline or hemispheric location in either the anterior, posterior, or flocculonodular lobe. For scientific research purposes, very small cerebellar infarcts can be classified even more precisely in terms of affected lobule(s).
De Cocker/van Veluw/Fowkes/Luijten/ Mali/Hendrikse 


\section{Acknowledgements}

We would like to thank Roy Sanders and Karin van Rijnbach (Multimedia division, UMC Utrecht) for their assistance in the preparation of the figures.

The first author receives funding from the European Society of Neuroradiology for a research fellowship in neuroradiology (European Exchange Program).

\section{Disclosure Statement}

None.

\section{References}

1 Amarenco P, Kase CS, Rosengart A, Pessin MS, Bousser M-G, Caplan LR: Very small (border zone) cerebellar infarcts. Brain 1993; 116:161-186.

2 Fisher CM: Lacunar infarcts: a review. Cerebrovasc Dis 1991;1:311-320.

3 Amarenco P, Lévy C, Cohen A, Touboul PJ, Roullet E, Bousser MG: Causes and mechanisms of territorial and nonterritorial cerebellar infarcts in 115 consecutive patients. Stroke 1994;25:105-112.

4 Min WK, Kim YS, Kim JY, Park SP, Suh CK: Atherothrombotic cerebellar infarction: vascular lesion-MRI correlation of 31 cases. Stroke 1999;30:2376-2381.

5 Canaple S, Bogousslavsky J: Multiple large and small cerebellar infarcts. J Neurol Neurosurg Psychiatry 1999;66:739-745.

-6 Schmahmann JD, Doyon J, McDonald D, Holmes C, Lavoie K, Hurwitz AS, Kabani N, Toga A, Evans A, Petrides M: Three-dimensional MRI atlas of the human cerebellum in proportional stereotaxic space. Neuroimage 1999; 10:233-260.

7 Marinković S, Kovacević M, Gibo H, Milisavljević M, Bumbasirević L: The anatomical basis for the cerebellar infarcts. Surg Neurol 1995;44:450-460.

$\$ 8$ Icardo JM, Ojeda JL, Garcia-Porrero JA, Hurle JM: The cerebellar arteries: cortical patterns and vascularization of the cerebellar nuclei. Acta Anat 1982;113:108-116.

9 Grimaldi G, Manto M: Topography of cerebellar deficits in humans. Cerebellum 2012; 11:336-351

10 Stoodley CJ, Schmahmann JD: Evidence for topographic organization in the cerebellum of motor control versus cognitive and affective processing. Cortex 2010;46:831-844.

11 Schmahmann JD, Macmore J, Vangel M: Cerebellar stroke without motor deficit: clinical evidence for motor and non-motor domains within the human cerebellum. Neuroscience 2009;162:852-861.

12 Barth A, Bogousslavsky J, Regli F: The clinical and topographic spectrum of cerebellar infarcts: a clinical-magnetic resonance imaging correlation study. Ann Neurol 1993;33:451456.

13 Bogousslavsky J, Regli F, Maeder P, Meuli R, Nader J: The etiology of posterior circulation infarcts: a prospective study using magnetic resonance imaging and magnetic resonance angiography. Neurology 1993;43:1528-1533.

14 Chaves CJ, Caplan LR, Chung CS, Tapia J, Amarenco P, Teal P, Wityk R, Estol C, Tettenborn B, Rosengart A, et al: Cerebellar infarcts in the New England Medical Center Posterior Circulation Stroke Registry. Neurology 1994; 44:1385-1390.

15 Terao S, Miura N, Osano Y, Takatsu S, Adachi K, Noda A, Sobue G: Multiple cerebellar infarcts: clinical and pathophysiologic features. J Stroke Cerebrovasc Dis 2005;14:193-198.

16 Tohgi H, Takahashi S, Chiba K, Hirata Y: Cerebellar infarction. Clinical and neuroimaging analysis in 293 patients. The Tohoku Cerebellar Infarction Study Group. Stroke 1993;24: 1697-1701.

17 Caplan LR, Wityk RJ, Glass TA, Tapia J, Pazdera L, Chang HM, Teal P, Dashe JF, Chaves CJ, Breen JC, Vemmos K, Amarenco P, Tettenborn B, Leary M, Estol C, Dewitt LD, Pessin MS: New England Medical Center Posterior Circulation registry. Ann Neurol 2004;56:389-398.

18 Caplan LR, Wong KS, Gao S, Hennerici MG: Is hypoperfusion an important cause of strokes? If so, how? Cerebrovasc Dis 2006;21:145-153.

19 Sedlaczek O, Caplan L, Hennerici M: Impaired washout - embolism and ischemic stroke: further examples and proof of concept. Cerebrovasc Dis 2005;19:396-401.

20 Kruit MC, Launer LJ, Ferrari MD, Van Buchem MA: Brain stem and cerebellar hyperintense lesions in migraine. Stroke 2006;37: 1109-1112.

21 Kurth T, Diener H-C: Migraine and stroke: perspectives for stroke physicians. Stroke 2012;43:3421-3426.

22 Reinhard M, Schork J, Allignol A, Weiller C, Kaube H: Cerebellar and cerebral autoregulation in migraine. Stroke 2012;43:987-993.

23 Macdonell RA, Kalnins RM, Donnan GA: Cerebellar infarction: natural history, prognosis, and pathology. Stroke 1987;18:849-855.

-24 Sypert GW, Alvord EC: Cerebellar infarction. A clinicopathological study. Arch Neurol 1975;32:357-363.

25 Brundel M, de Bresser J, van Dillen JJ, Kappelle LJ, Biessels GJ: Cerebral microinfarcts: a systematic review of neuropathological studies. J Cereb Blood Flow Metab 2012;32:425-436.

26 Gass A, Ay H, Szabo K, Koroshetz WJ: Diffusion-weighted MRI for the 'small stuff: the details of acute cerebral ischaemia. Lancet Neurol 2004;3:39-45.

27 van Veluw SJ, Zwanenburg JJ, Engelen-Lee J, Spliet WG, Hendrikse J, Luijten PR, Biessels GJ: In vivo detection of cerebral cortical microinfarcts with high-resolution 7T MRI. J Cereb Blood Flow Metab 2013;33:322-329.

28 Edlow JA, Newman-Toker DE, Savitz SI: Diagnosis and initial management of cerebellar infarction. Lancet Neurol 2008;7:951-964.

29 Exner C, Weniger G, Irle E: Cerebellar lesions in the PICA but not SCA territory impair cognition. Neurology 2004;63:2132-2135.

30 Schmahmann JD, Sherman JC: The cerebellar cognitive affective syndrome. Brain 1998;121: 561-579.

31 Kumral E, Kisabay A, Ataç C, Calli C, Yunten $\mathrm{N}$ : Spectrum of the posterior inferior cerebellar artery territory infarcts. Clinical-diffusion-weighted imaging correlates. Cerebrovasc Dis 2005;20:370-380.

32 Mangla R, Kolar B, Almast J, Ekholm SE: Border zone infarcts: pathophysiologic and imaging characteristics. Radiographics 2011;31: 1201-1215.

33 Kruit MC, Launer LJ, Ferrari MD, Van Buchem MA: Infarcts in the posterior circulation territory in migraine. The population-based MRI CAMERA study. Brain 2005;128:2068-2077.

-34 Tatu L, Moulin T, Bogousslavsky J, Duvernoy H: Arterial territories of human brain: brainstem and cerebellum. Neurology 1996;47:1125-1135.

- 35 Cormier PJ, Long ER, Russell EJ: MR imaging of posterior fossa infarctions: vascular territories and clinical correlates. Radiographics 1992;12:1079-1096.

36 Savitz SI, Caplan LR, Edlow JA: Pitfalls in the diagnosis of cerebellar infarction. Acad Emerg Med 2007;14:63-68.

-37 Simmons Z, Biller J, Adams HP, Dunn V, Jacoby CG: Cerebellar infarction: comparison of computed tomography and magnetic resonance imaging. Ann Neurol 1986;19:291-293.

38 Katzan IL, Abou-Chebl A, Andrefsky JC, Krieger DW, Ross JS: MR imaging of posterior fossa infarcts FLAIR versus T2-weighted sequences (abstract). Stroke 2000;32:350.

39 Wardlaw JM, Armitage P, Dennis MS, Lewis S, Marshall I, Sellar R: The use of diffusionweighted magnetic resonance imaging to identify infarctions in patients with minor strokes. J Stroke Cerebrovasc Dis 2000;9:70-75. 